\title{
Analysis of the link between injuries on forest trees and presence of harmful fungal organisms
}

\author{
Miroslava MARKOVIC ${ }^{1 *}$, Dragan MITIC ${ }^{2}$, Snezana RAJKOVIC ${ }^{1}$, Ljubinko RAKONJAC ${ }^{1}$, \\ Aleksandar LUCIC ${ }^{1}$, Miroslav MARKOVIC ${ }^{3}$ and Radoslav RAJKOVIC ${ }^{4}$ \\ ${ }^{1}$ Miroslava Markovic, Institute for Forestry, Kneza Viseslava 3, 11030 Belgrade, Serbia. \\ ${ }^{2}$ IRITEL, Belgrade, Serbia. \\ ${ }^{3}$ Institute of Lowland Forestry and Environment, Antona Cehova 13, Novi Sad, Serbia. \\ ${ }^{4}$ University of Belgrade, Faculty of Mechanical Engineering, Inovation Centre, Belgrade, Serbia.
}

Accepted 5 September, 2013

\begin{abstract}
This research focus on the occurrence of pathogenic microorganisms on beech trees relative to the presence of tree injuries, with the aim to ensure protection and preservation of this species in Serbia. The research was conducted in eastern Serbia, in a hillside beech forest Fagetum moesiacae submontanum of generative origin. The testing was carried out on two sites over 51 testing plots, with a total of 829 trees and 21 species of identified fungi. On the first site it was found that the appearance of fungi primarily depends on the presence of mechanical damage on trees (as much as $73.46 \%$ ), while the presence of abiotic damage has almost no bearing (only $3.21 \%$ ). On the second site there was a strong correlation link between the occurrence of fungi and presence of mechanical damage $-51.88 \%$, as well as between the fungi and abiotic damage $-47.96 \%$. The health condition of high beech stands was found to be heavily dependent on careful and proper manipulation during harvesting, while each injury inflicted on a beech live tree during logging opens the door to infection with pathogenic microorganisms.
\end{abstract}

Key words: Injuries, environmental factors, fungi, beech forests

\section{INTRODUCTION}

Given the fact that the global wood coverage in Serbia is currently significantly below the European average, the country's forestry is primarily tasked with preservation of the national treasure (wealth) of natural forests, which in turn necessitates that the strategy for preservation of biodiversity and genetic resources be oriented primarily towards the economically most valuable species of trees. The national inventory of Serbia's forests in the total volume and bulk growth is dominated by beech, whose presence amounts to $42.4 \%$, or $32.3 \%$ (Bankovic et al., 2009). Due to their presence in the forest reserves of Serbia, beech forests undoubtedly have the greatest significance, which quite justifiably leads to conclusion that management of beech forests is an extremely complex yet significant task for this region. Finally, the majority of the available literature does not address these concerns with regard to commercial interests (Kiser, 2009). All the above reasons led us to focus our research on our most important tree species - beech.

In the available literature sources, the quality of tall beech forests in Serbia is most frequently referred to in descriptive and general terms - as unsatisfactory and in need of improvement (Karadzic and Milijasevic, 2005; Miletic et al., 2006; Tabakovic-Tosic and Markovic, 2003; Milovanovic et al., 2004), which inevitably commands that closer attention be paid to detailed research in this field. 
Problems of tree damage in forest stands are related to abiotic factors and widespread implementation of mechanical harvesting in forestry since the second half of the 20th century (Say, 1999). The cause of beech forests dieback is a consequence of simultaneous negative impact of climate changes, management and biotic factors. Among these a special place belongs to man, whose irrational exploitation of beech forests resulted in Serbia's area under forest being cut almost in half. Felling of beech woodland that occurred in the past (in particular immediately after World War II) was largely conducted not as regeneration harvests, but almost exclusively for exploitation purposes. As a consequence of such stewardship, forests have become extremely sensitive to harmful effects of numerous abiotic and biotic factors.

Preservation of beech forests is additionally complicated by the fact that beech wood is highly vulnerable and thus an excellent base for development of numerous parasitic and saprophytic organisms, among which is primarily parasitic fungi. In beech coppice forests in Serbia, a total of 147 species of fungi were found on beech trees, out of which 33 species occur on crowns, fruits and young crop, 56 species occur on leaves and bark of the branches and the trunk, whereas 58 species of fungi cause rot and coloration of wood (Karadzic, 2003).

Harmful fungal organisms occur in stands as a consequence of effects of a whole complex of factors, where among the decisive ones are climatic conditions during the year and the overall health condition of trees. Since climatic changes are obviously beyond our scope of influence, other factors affecting health and general condition of trees should be investigated more closely.

It is given that not all harmful fungal organisms participate equally in tree dieback, meaning that the most significant pathogens are those that cause dangerous diseases, as well as wood destructors that start their development as parasites on living trees and continue as saprophytes on fallen trees (Ivkovic et al., 2007; Markovic et al., 2011).

Starting from the assumption that injuries on trees (caused by either abiotic or biotic factors) directly impact the vitality and condition of trees and pave the way to colonization and development of numerous fungal organisms, it is crucial to analyse the ratio between the number of injuries and the number and significance of the present fungi. The study by Kiser (2009) fails to support the existing models of active tree response to invasion and instead corroborates the model of passive response to fungal invasion following damage to wood tissue. The analysis of the above ratio would indicate to which degree the number of injuries on trees is a decisive factor in colonization of fungal organisms with the aim to contribute to the most rational approach to use of beech timber while preserving beech stands in Serbia to the maximum extent, which was the primary practical goal of research described in this paper.

\section{MATERIALS AND METHODS}

The sites selected for research were the ones on which the observation method revealed a large number of injuries on trees. The paper provides an analysis of the impact of tree injuries on occurrence of pathogenic and epixylic fungi on live trees in beech woodlands.

The research was carried out in the forest holding "Severni Kucaj" (North Kucaj) in Kucevo, forest administration Kucevo, Eastern Serbia, in a hillside forest of Fagetum moesiacae submontanum beech of generative origin. The first tested site was located in the Administration unit Majdan Kucajna, division 33 (Figure 1). The second site was in administration unit Crni Vrh, division 42 , sections $a$ and $b$ (Figure 1 ). The research included $a$ total of 829 beech trees on 51 test plots.

The area in which the research was conducted (territory of Kucevo Municipality) lies in the hinterland of the Danube on one side, surrounded by Homolje Mountains on the other. The terrain configuration varies from lowland (in the lower stream of the Pek River) to hilly and mountainous encompassing the wooded areas of North Kucaj. The altitude of the area ranges between 120 and 920 $\mathrm{m}$.

The latitude, altitude and position of the basin in the Pek River stream, relative to the dominant directions of movement of air masses, partake in formation of general and specific climatic features of Kucevo Municipality. The climate in the area is moderately continental with strong highland influences. The region receives the most rainy days during May and June (when the research was conducted, as warm and humid weather favours occurrence of a multitude of carpophores) and the fewest in September and October. The average annual temperature is $11.3^{\circ} \mathrm{C}$, and speaking in general terms, the area has stable changes of climatic elements over the year.

The $500 \mathrm{~m}^{2}$ trial experimental plots were circular, placed in the stands at $100 \times 100 \mathrm{~m}$ distances (according to the method described by Koprivica et al., 2008). Each experimental plot included between 4 and 24 trees on site I, and between 8 and 27 trees on site II. Injuries noted on each tree were classified as mechanic (injuries from felling and hauling during harvest) and abiotic (injuries from wind, snow, ice, frost and excessive insulation that caused bark inflammation). The fungi present on trees were identified through macroscopic examination.

All the received results underwent detailed statistical processing, whereby Microsoft Excel was used in order to obtain the Pearson linear correlation coefficient.

\section{RESULTS}

Tables 1 and 2 presents an overview of the fungi identified on site I and II according to their frequency of occurrence. For example, in Table 1 it is evident that the first four fungi are present in all experimental plots (noted on 12.6 to $29 \%$ of all trees), whereas the presence of the latter 8 fungi was noted, on the average, in only four plots and no more than 0.3 to $0.9 \%$ of trees. The fungi with ordinal numbers 5 through 9 are present on over $50 \%$ of experimental plots (or 6.5 to $11.1 \%$ of trees), while the fungi with ordinal numbers 8 through 13 were identified on less than $50 \%$ of the plots and spread on 1 to $20 \%$ of the tested trees.

Tables 1 and 2 presents fungi classified according to their significance, where those with three stars represent dangerous fungi with high significance, the fungi with two 
SITE: I

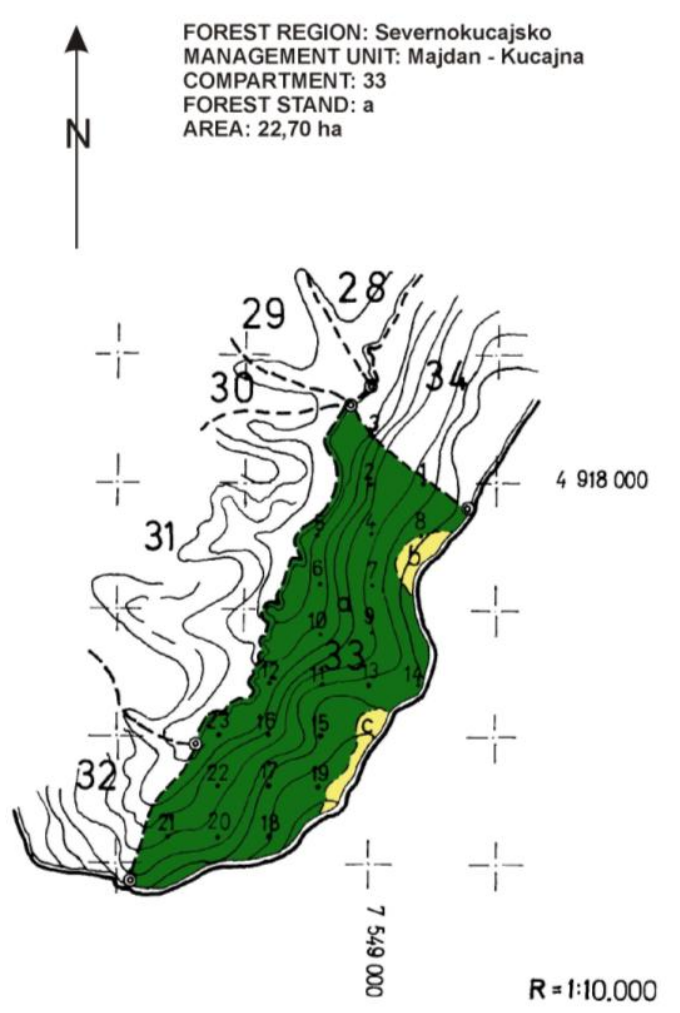

SITE: ॥

FOREST REGION: Severnokucajsko MANAGEMENT UNIT: Crni Vrh COMPARTMENT: 42 FOREST STAND: $a, b$ AREA: $a=17,52$ ha $\mathrm{b}=11,97$ ha<smiles>CC1(C)CCCC1</smiles>

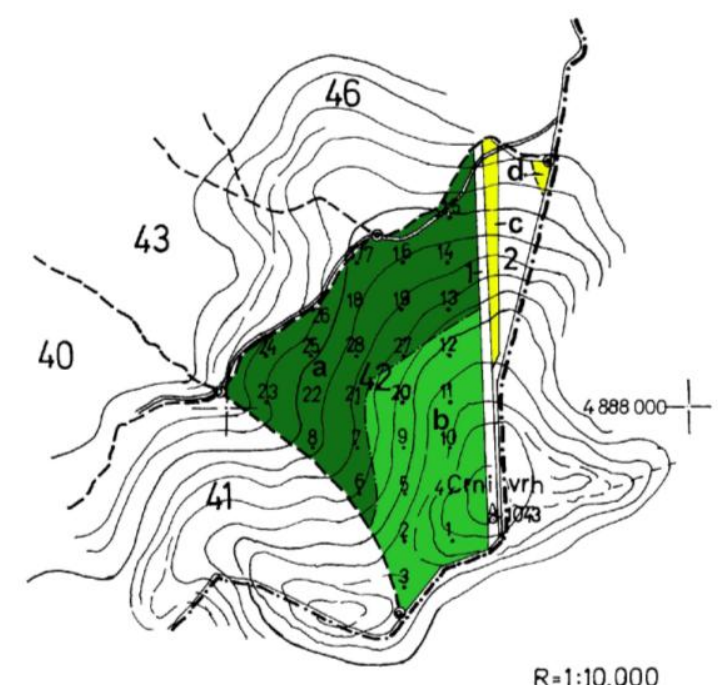

$R=1: 10.000$

Figure 1. Map of first and second sites (Sites I and II).

Table 1. Fungi identified on site I - Administration unit Majdan Kucajna, division 33.

\begin{tabular}{clccc}
\hline $\begin{array}{c}\text { Ordinal number } \\
\text { of fungus }\end{array}$ & Type of fungus & $\begin{array}{c}\text { Significance } \\
\text { of fungus }\end{array}$ & $\begin{array}{c}\% \text { plots on which the } \\
\text { fungus is present }\end{array}$ & $\begin{array}{c}\text { \% trees on which the } \\
\text { fungus is present }\end{array}$ \\
\hline 1 & Apiognomonia errabunda & $* \star *$ & 100.0 & 29.0 \\
2 & Coriolus sp. & $* *$ & 100.0 & 24.6 \\
3 & Hypoxylon sp. & $* *$ & 100.0 & 8.9 \\
4 & Stereum sp. & $*$ & 100.0 & 12.6 \\
5 & Diatrype stigma & $* * *$ & 65.2 & 11.1 \\
6 & Fomes fomentarius & $* *$ & 57.0 & 6.5 \\
7 & Trametes sp. & $* *$ & 52.2 & 8.6 \\
8 & Diatrype disciformis & $* * *$ & 47.8 & 20.9 \\
9 & Nectria galligena & $* * *$ & 30.4 & 4.0 \\
10 & Armillaria mellea & $* *$ & 26.0 & 1.2 \\
11 & Lenzites trabaea & $* * *$ & 17.4 & 1.8 \\
12 & Nectria coccinea & $* *$ & 8.7 & 1.2 \\
13 & Fomes igniarius & $* * *$ & 8.7 & 1.5 \\
14 & Pleurotus ostreatus & $* * *$ & 4.3 & 0.6 \\
15 & Poria obliqua & 4.3 & 0.3 \\
16 & Dedalea quercina & $* *$ & 4.3 & 0.9 \\
17 & Exidia recisa & $*$ & 4.3 & 0.3 \\
18 & Hydnum coraloides & $*$ & 4.3 & 0.3 \\
19 & Auricullaria auricila judae & - & 4.3 & 0.3 \\
20 & Auricullaria mesenterica & - & 4.3 & 0.3 \\
21 & Bulgaria polymorpha & - & 4.3 & 0.6 \\
\hline
\end{tabular}


Table 2. Fungi identified on site II - Administration unit Crni Vrh, division 42, sections a, b.

\begin{tabular}{clccc}
\hline $\begin{array}{c}\text { Ordinal number } \\
\text { of fungus }\end{array}$ & Type of fungus & $\begin{array}{c}\text { Significance of } \\
\text { fungus }\end{array}$ & $\begin{array}{c}\text { \% plots on which the } \\
\text { fungus is present }\end{array}$ & $\begin{array}{c}\text { \% trees on which the } \\
\text { fungus is present }\end{array}$ \\
\hline 1 & Coriolus sp. & $* * *$ & 100.0 & 18.3 \\
2 & Apiognomonia errabunda & $* * *$ & 82.0 & 15.0 \\
3 & Hypoxylon sp. & $* * *$ & 78.6 & 6.5 \\
4 & Nectria coccinea & $* * *$ & 64.3 & 7.1 \\
5 & Nectria galligena & $*$ & 53.6 & 6.5 \\
6 & Diatrype stigma & $* * *$ & 35.7 & 5.7 \\
7 & Fomes fomentarius & $*$ & 21.0 & 2.2 \\
8 & Hydnum coraloides & $* *$ & 14.3 & 0.8 \\
9 & Stereum sp. & $* *$ & 10.7 & 1.2 \\
10 & Diatrype disciformis & $* * *$ & 7.1 & 1.4 \\
11 & Armillaria mellea & $* *$ & 7.0 & 0.6 \\
12 & Dedalea quercina & & 3.6 & 0.2 \\
\hline
\end{tabular}

stars have medium significance, the fungi with one star have low significance, and those without stars have no significance. Under the classification proposed by Karadzic (2003) and Ivkovic et al. (2007), the present fungi were classified as follows:

*** Fungi with high significance: The highest significance is given to fungi that act that both as parasites and saprophytes, that is, whose activity starts on standing, live trees and then persists on dead trees, following the harvest. These species of epyxilic fungi demonstrate a very high level of destruction and degrade primarily lignin, as well as cellulose and hemicelluloses, but to a lesser degree. Among the identified fungi, this group comprises Armillaria mellea, Fomes fomentarius, Pleurotus ostreatus and Poria obliqua. Besides the above-named wood-decay fungi, this group also includes the following pathogenic fungi: Apiognomonia errabunda, Nectria coccinea and Nectria galligena).

** Fungi with medium significance: This group comprises the fungi that cause a somewhat lower degree of destruction, but appear on both injured, weakened trees and the freshly harvested ones. This group is represented by Coriolus versicolor, Dedalea quercina, Diatrype disciformis, Hypoxylon sp., Stereum sp. and Trametes sp.

* Fungi with low significance: This group comprises the fungi that appear on rotting trees, frequently causing their complete degradation. Among the identified fungi, this group includes Exidia recisa, Hydnum coraloides and Diatrype stigma.

- Fungi with no significance: Representatives of this group identified on the tested sites include Auricullaria auricula judae, Auricullaria mesenterica and Bulgaria polymorpha.

Table 3 presents the testing results for the total number of the present fungi and the total number of mechanical and abiotic damage on site II.

One of the most significant fungi identified on the tested sites is Nectria coccinea (Pers. Ex Fr.) Fries., which together with the insect Cryptococcus fagisuga Lind. causes the so-called "beech bark disease". On site I, this fungus was found on $1.2 \%$ of trees or on 3 experimental plots (1, 3 and 9), whereas on site II its spread was much greater and covered $7.1 \%$ of trees or almost two-thirds of experimental plots. This disease is lately being regarded as a major factor compromising normal development of beech trees, which merits special attention given the fact that it is spreading over ever-larger areas. Measures undertaken against this fungus are classified into several categories:

i) Biological preventive measures, including use of predators and super-parasites against insects (prior to infection with fungus).

ii) Bio-control of the fungus by means of antagonists (once the infection occurs).

iii) Silvicultural measures - removal of diseased trees (in advanced stages of the infection).

iv) Chemical measures, which are non-economical for forests and thus applied only to parks and alleys of trees.

It is important to note that following the infection of beech trees with this fungus, the necrotic bark sections very quickly get infested by wood-decaying fungi and wooddestroying insects, which also play a role in rapid tree decay and extinction of beech trees, according to Karadzic (2003).

Data presented in Table 3 (which refers to Site I) were used to form graphs (Figures 2 through 5). Figure 2 presents the number of detected fungi (comprising the number of dangerous fungi $-\mathrm{y}_{1}$, number of other fungi $y_{2}$, and the total number of fungi - $y_{3}$ ) per individual plot, as well as the number of trees per corresponding plot. Figure 2 shows that the number of dangerous fungi 
Table 3. Overview of attack by fungi and injuries on beech trees on Site I - Administration unit Majdan Kucajna, division 33.

\begin{tabular}{|c|c|c|c|c|c|c|c|c|}
\hline \multirow[b]{2}{*}{$\begin{array}{l}\text { Ordinal } \\
\text { no. of } \\
\text { plot }\end{array}$} & \multirow[b]{2}{*}{$\begin{array}{l}\left(x^{\prime}\right) \text { No. of } \\
\text { trees on } \\
\text { the plot }\end{array}$} & \multicolumn{3}{|c|}{ Number of fungi found } & \multirow{2}{*}{$\begin{array}{c}\left(\mathbf{x}_{1}\right) \text { Number of } \\
\text { mechanical injuries } \\
\text { (damage from } \\
\text { hauling and felling } \\
\text { during harvest) } \\
\end{array}$} & \multirow{2}{*}{$\begin{array}{l}\left.\text { (x } x_{2}\right) \text { Number of abiotic injuries } \\
\text { (damage from wind, snow, } \\
\text { ice, frost and excessive } \\
\text { insulation - bark } \\
\text { inflammation) }\end{array}$} & \multirow{2}{*}{$\begin{array}{c}\left(\mathrm{x}_{3}\right) \text { Total } \\
\text { number of } \\
\text { mechanical and } \\
\text { abiotic injuries }\end{array}$} & \multirow[b]{2}{*}{$\begin{array}{l}\text { Index } \\
\left(x_{3} / x^{\prime}\right)\end{array}$} \\
\hline & & $\begin{array}{c}\left(y_{1}\right) \text { No. of } \\
\text { dangerous } \\
\text { fungi }\end{array}$ & $\begin{array}{l}\left(y_{2}\right) \text { No. } \\
\text { of other } \\
\text { fungi }\end{array}$ & $\begin{array}{l}\left(\mathrm{y}_{3}\right) \text { Total } \\
\text { number of } \\
\text { fungi }\end{array}$ & & & & \\
\hline 1 & 12 & 1 & 3 & 4 & 2 & 3 & 5 & 0.42 \\
\hline 2 & 24 & 1 & 4 & 5 & 3 & 4 & 7 & 0.29 \\
\hline 3 & 9 & 1 & 3 & 4 & 2 & 3 & 5 & 0.56 \\
\hline 4 & 11 & 1 & 3 & 4 & 1 & 3 & 4 & 0.36 \\
\hline 5 & 16 & 1 & 5 & 6 & 8 & 1 & 9 & 0.56 \\
\hline 6 & 9 & 1 & 4 & 5 & 6 & 2 & 8 & 0.89 \\
\hline 7 & 16 & 4 & 6 & 10 & 15 & 6 & 21 & 0.06 \\
\hline 8 & 12 & 4 & 6 & 10 & 20 & 9 & 29 & 2.42 \\
\hline 9 & 23 & 6 & 9 & 15 & 27 & 4 & 31 & 1.35 \\
\hline 10 & 15 & 1 & 6 & 7 & 3 & 1 & 4 & 0.27 \\
\hline 11 & 21 & 2 & 6 & 8 & 17 & 9 & 26 & 1.24 \\
\hline 12 & 18 & 3 & 6 & 9 & 21 & 3 & 24 & 1.33 \\
\hline 13 & 8 & 1 & 5 & 6 & 14 & 2 & 16 & 2.00 \\
\hline 14 & 11 & 2 & 6 & 8 & 15 & 3 & 18 & 1.64 \\
\hline 15 & 19 & 2 & 6 & 8 & 11 & 10 & 21 & 1.11 \\
\hline 16 & 4 & 1 & 5 & 6 & 4 & 1 & 5 & 1.25 \\
\hline 17 & 15 & 3 & 5 & 8 & 16 & 42 & 20 & 1.33 \\
\hline 18 & 9 & 1 & 4 & 5 & 9 & 6 & 11 & 1.22 \\
\hline 19 & 23 & 4 & 8 & 12 & 19 & 7 & 25 & 1.09 \\
\hline 20 & 8 & 2 & 4 & 6 & 7 & 3 & 14 & 1.75 \\
\hline 21 & 8 & 1 & 5 & 6 & 14 & 3 & 17 & 2.12 \\
\hline 22 & 17 & 4 & 6 & 10 & 12 & 8 & 20 & 1.18 \\
\hline 23 & 16 & 3 & 7 & 10 & 23 & 4 & 27 & 1.69 \\
\hline
\end{tabular}

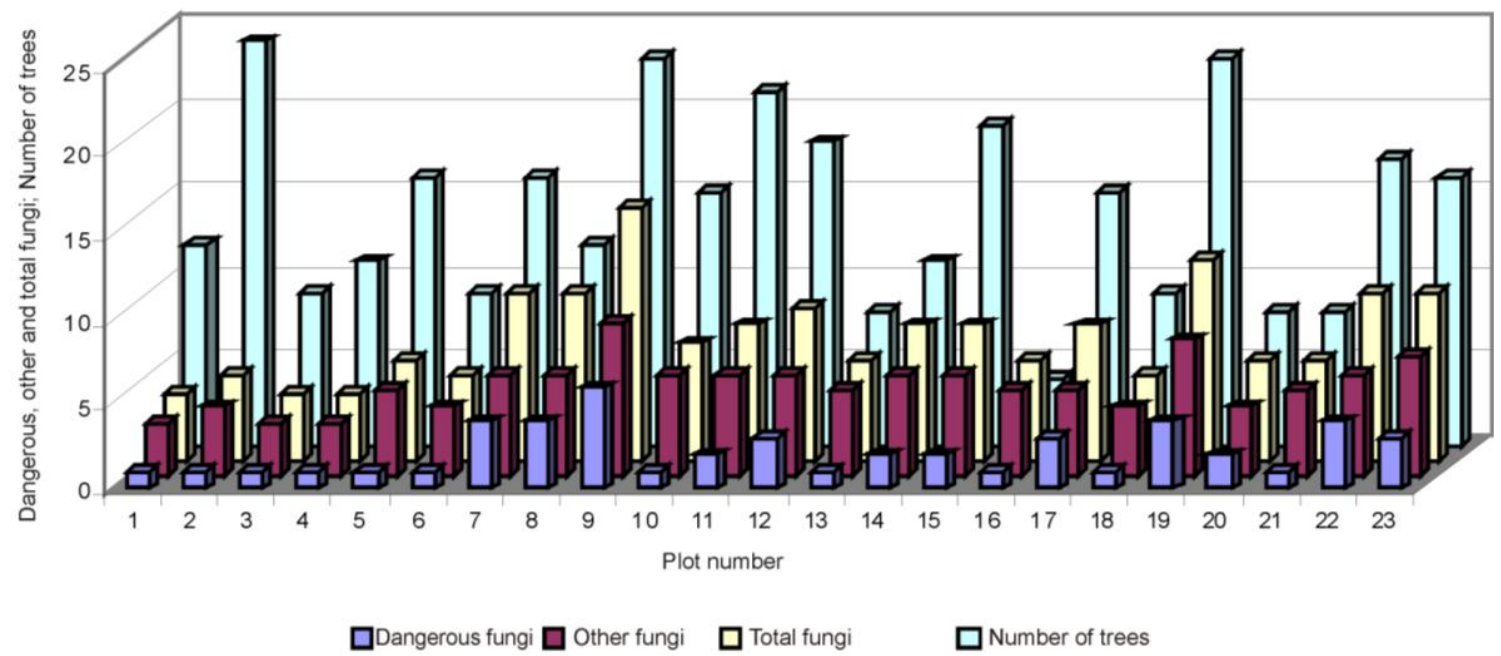

Figure 2. Site I - number of trees, number of dangerous and other fungi and total number of fungi per plot (from Table 3).

relative to the total number of fungi (in percentages between 16.6 and $40 \%$ ) is much lower than the number of other fungi relative to the total number of fungi (between
83.3 and $60 \%$ ). This means that dangerous fungi always occur in smaller numbers than other fungi. It is also worth noting that a certain number of trees on each plot were 


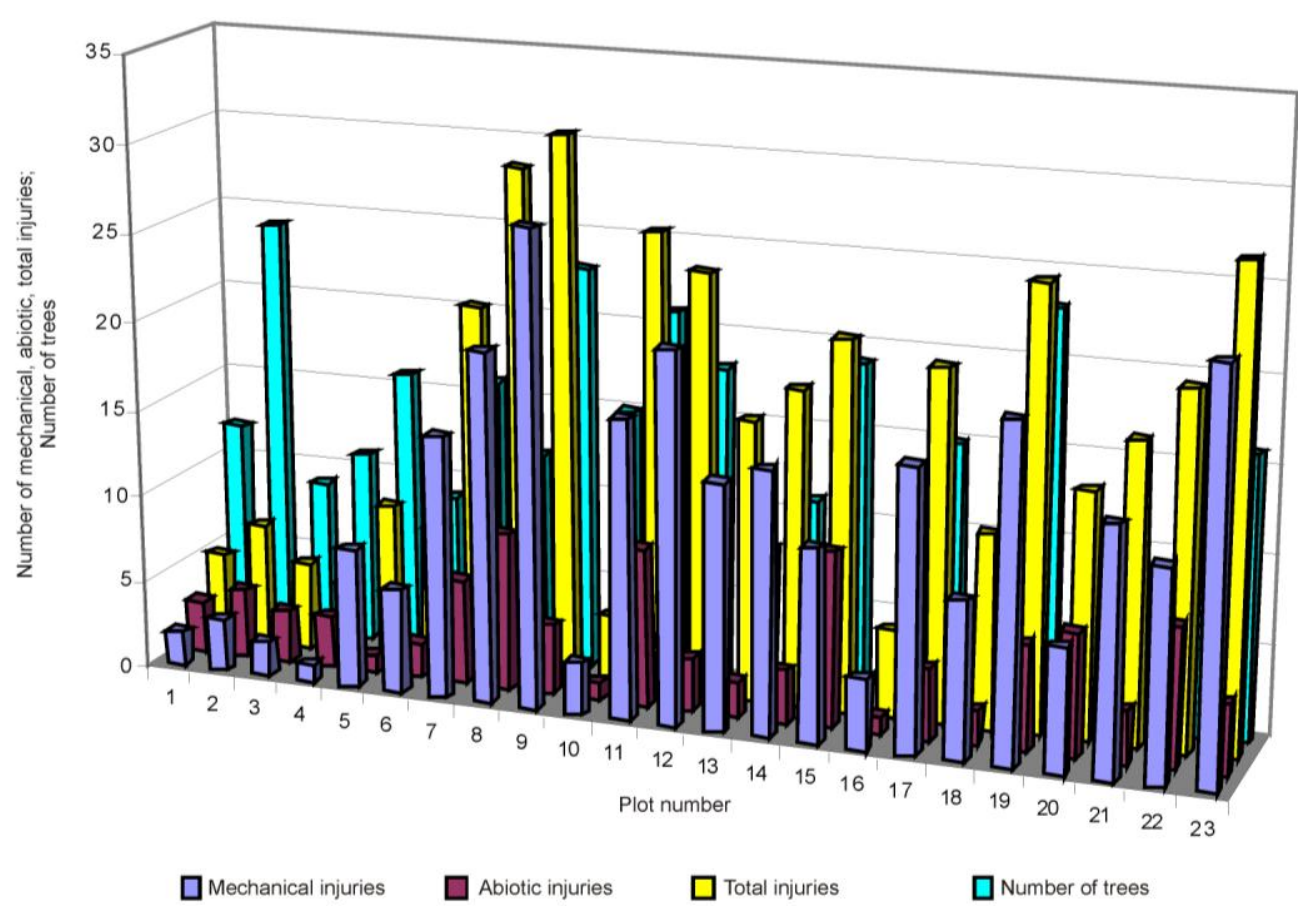

Figure 3. Site I - number of trees, number of mechanical injuries, number of abiotic injuries and total number of injuries per plot (from Table 3).

not infected by fungi, with the exception of plot no. 16 on which all trees were infected with some type of fungi (Table 1).

Figure 3 presents the number of mechanical injuries $\left(x_{1}\right.$ - damage from hauling and felling during harvest), the number of abiotic injuries $\left(\mathrm{x}_{2}-\right.$ damage from wind, snow, ice, frost and excessive insulation - bark inflammation) and the total number of mechanical and abiotic injuries $x_{3}$ per individual plots, as well as the number of trees per corresponding plot. It is evident from Figure 3 that the number of mechanical injuries relative to the total number of injuries (ranging in percentages between 50 and $88.88 \%$ ) is higher than the number of abiotic injuries relative to the total number of injuries (between 50 and $11.11 \%)$. This trend was noted on most sites, with the exception of sites no. 1 through 4, where the situation is reversed. It is also evident that there was a certain number of injury-fee trees on a few plots (Sites no. 1 through 5), whereas all trees on all other plots sustained some type of damage.

Figure 4 presents the number of dangerous fungi per plot, ranging from one (plots no. 1 through 6 , no. 10 , no. 13 , no. 18 and no. 21) to maximum six dangerous fungi (plot no. 9). On other plots the number of dangerous fungi varies between two and four per plot.

Figure 5 presents the ratio between the total number of fungi per tree and the total number of injuries per tree. Figure 5 demonstrates that the ratio of total number of fungi per tree is small than the ratio of total number of injuries per tree on most sites, except on sites nos. 7 and
10.

Data presented in Table 4 (which refers to Site II) were used to form graphs (Figures 6 through 9). Figure 6 presents the number of detected fungi (consisting of the number of dangerous fungi - $\mathrm{y}_{1}$, number of other fungi $y_{2}$, and the total number of fungi $-y_{3}$ ) per individual plot, as well as the number of trees per plot. From Figure 6 it is evident that the number of dangerous fungi relative to the total number of fungi ranges in percentages from 0 to $66.66 \%$, whereas the number of other fungi relative to the total number of fungi goes in percentages between 33.33 and $100 \%$. This means that the number of dangerous fungi on some plots is higher, and on the other plots lower than the number of other fungi (Table 2). It is also evident that on all plots there was a certain number of trees not infected by fungi, while on some plots no trees were infected by dangerous fungi (plots nos. 7, 8, 21, 24 and 25).

Figure 7 demonstrates the number of mechanical injuries (including damage from hauling and felling during harvest $-x_{1}$, the number of abiotic injuries: damage from wind, snow, ice, frost and excessive insulation, bark inflammation $-x_{2}$ and the total number of mechanical and abiotic injuries - $x_{3}$ per individual plot, as well as the number of trees per corresponding plots). It is evident from Figure 7 that the number of mechanical injuries relative to the number of total injuries in most cases (on the majority of sites) is below the number of abiotic injuries relative to the number of total injuries, with the exception of sites nos. 13,14,15, 17 and 19, where the 


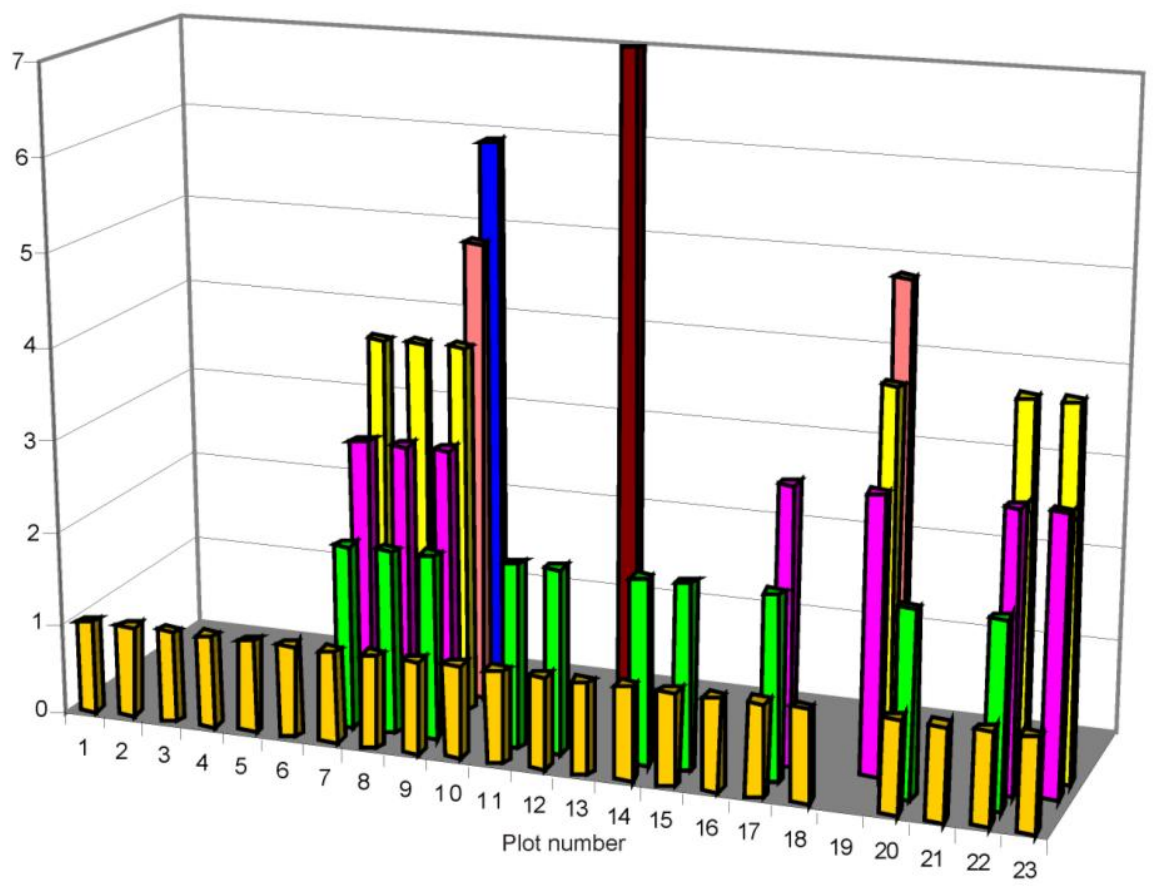

$\square$ Rb. $1 \square$ Rb. $6 \square$ Rb. $9 \square$ Rb. $10 \square$ Rb. $12 \square$ Rb. $14 \square$ Rb. 15

Figure 4. Site I - number of dangerous fungi per plot (from Table 1).

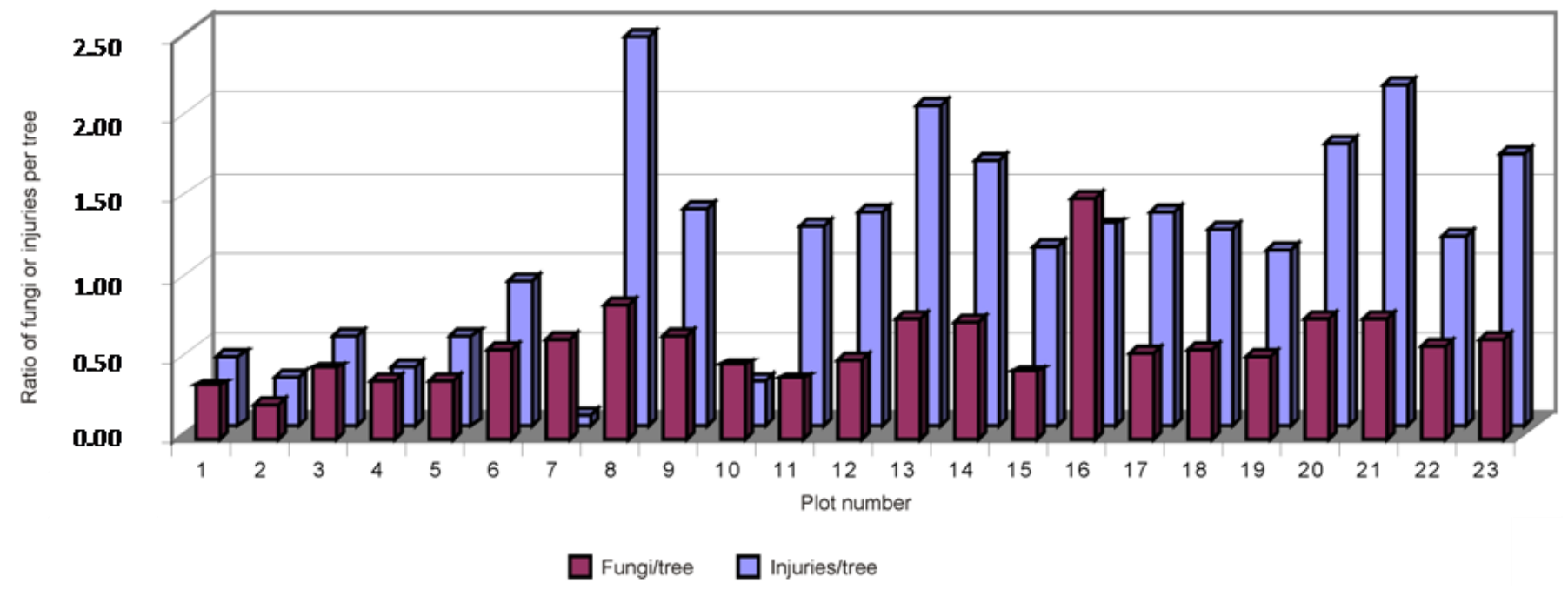

Figure 5. Site I - ratio between the total number of fungi per tree and the total number of injuries per tree (from Table 3)

situation is reversed. Furthermore, it is noticeable that there was a certain number of injury-fee trees on a few plots (plots no. 14, 15, 22, 23 and 24), whereas all trees on all other plots sustained some type of damage.

Figure 8 presents the number of dangerous fungi per individual plot, ranging from one (plots no. 18 and 23) to maximum of five dangerous fungi (plots nos. 1 and 3 ). On other plots the number of dangerous fungi varies between two and four per plot, while on some plots there was no infection with dangerous fungi at all (nos. 7, 8, 21, 24 and 25).

Figure 9 show ratios between the total number of fungi per tree and the total number of injuries per tree. From Figure 9 it is evident that on all sites the ratio of total number of fungi per tree is lower than the ratio of the total number of injuries per tree.

Correlation is a statistical procedure used to calculate the relationship between two variables $(x, y)$. The numeric 
Table 4. Overview of attack by fungi and injuries on beech trees on site II - Administration unit Crni Vrh, division 42, sections a, b.

\begin{tabular}{|c|c|c|c|c|c|c|c|c|}
\hline \multirow[b]{2}{*}{$\begin{array}{l}\text { Ordinal } \\
\text { no. of } \\
\text { plot }\end{array}$} & \multirow[b]{2}{*}{$\begin{array}{l}\left(x^{\prime}\right) \text { No. of } \\
\text { trees on } \\
\text { the plot }\end{array}$} & \multicolumn{3}{|c|}{ Number of fungi found } & \multirow{2}{*}{$\begin{array}{c}\left(\mathbf{x}_{1}\right) \text { Number of } \\
\text { mechanical injuries } \\
\text { (damage from } \\
\text { hauling and felling } \\
\text { during harvest) } \\
\end{array}$} & \multirow{2}{*}{$\begin{array}{l}\left(\mathbf{x}_{2}\right) \text { Number of abiotic } \\
\text { injuries (damage from } \\
\text { wind, snow, ice, frost } \\
\text { and excessive insulation } \\
\text { - bark inflammation) }\end{array}$} & \multirow{2}{*}{$\begin{array}{c}\left(x_{3}\right) \text { Total } \\
\text { number of } \\
\text { mechanical } \\
\text { and abiotic } \\
\text { injuries }\end{array}$} & \multirow[b]{2}{*}{ Index $\left(x_{3} / x^{\prime}\right)$} \\
\hline & & $\begin{array}{c}\left(y_{1}\right) \text { No. of } \\
\text { dangerous } \\
\text { fungi }\end{array}$ & $\begin{array}{l}\left(\mathrm{y}_{2}\right) \text { No. } \\
\text { of other } \\
\text { fungi }\end{array}$ & $\begin{array}{c}\left(\mathrm{y}_{3}\right) \text { Total } \\
\text { number of } \\
\text { fungi }\end{array}$ & & & & \\
\hline 1 & 20 & 5 & 6 & 11 & 16 & 42 & 58 & 2.90 \\
\hline 2 & 27 & 3 & 3 & 6 & 12 & 7 & 19 & 0.70 \\
\hline 3 & 22 & 5 & 3 & 8 & 16 & 34 & 50 & 2.27 \\
\hline 4 & 20 & 4 & 2 & 6 & 4 & 34 & 38 & 1.90 \\
\hline 5 & 21 & 3 & 3 & 6 & 10 & 17 & 27 & 1.29 \\
\hline 6 & 9 & 1 & 2 & 3 & 4 & 8 & 12 & 1.33 \\
\hline 7 & 11 & 0 & 3 & 3 & 7 & 7 & 14 & 1.27 \\
\hline 8 & 14 & 0 & 2 & 2 & 2 & 7 & 9 & 0.64 \\
\hline 9 & 22 & 3 & 2 & 5 & 5 & 7 & 12 & 0.54 \\
\hline 10 & 17 & 4 & 2 & 6 & 8 & 37 & 86 & 5.06 \\
\hline 11 & 10 & 1 & 2 & 3 & 2 & 19 & 19 & 1.90 \\
\hline 12 & 12 & 2 & 2 & 4 & 8 & 14 & 22 & 1.83 \\
\hline 13 & 16 & 2 & 2 & 4 & 10 & 7 & 17 & 1.06 \\
\hline 14 & 23 & 3 & 2 & 5 & 10 & 3 & 13 & 0.56 \\
\hline 15 & 21 & 3 & 2 & 5 & 14 & 2 & 16 & 0.76 \\
\hline 16 & 25 & 2 & 5 & 7 & 16 & 27 & 43 & 1.72 \\
\hline 17 & 19 & 1 & 3 & 4 & 11 & 9 & 20 & 1.05 \\
\hline 18 & 14 & 1 & 2 & 3 & 3 & 11 & 14 & 1.00 \\
\hline 19 & 23 & 4 & 2 & 6 & 14 & 10 & 24 & 1.04 \\
\hline 20 & 19 & 3 & 2 & 5 & 5 & 17 & 22 & 1.16 \\
\hline 21 & 11 & 0 & 2 & 2 & 6 & 8 & 14 & 1.27 \\
\hline 22 & 23 & 3 & 2 & 5 & 1 & 18 & 19 & 0.83 \\
\hline 23 & 20 & 1 & 2 & 3 & 3 & 9 & 12 & 0.60 \\
\hline 24 & 20 & 0 & 2 & 2 & 1 & 3 & 4 & 0.20 \\
\hline 25 & 8 & 0 & 2 & 2 & 1 & 15 & 16 & 2.00 \\
\hline 26 & 26 & 3 & 2 & 5 & 12 & 20 & 32 & 1.23 \\
\hline 27 & 18 & 3 & 2 & 5 & 15 & 15 & 30 & 1.67 \\
\hline 28 & 13 & 3 & 2 & 5 & 7 & 8 & 15 & 1.15 \\
\hline
\end{tabular}

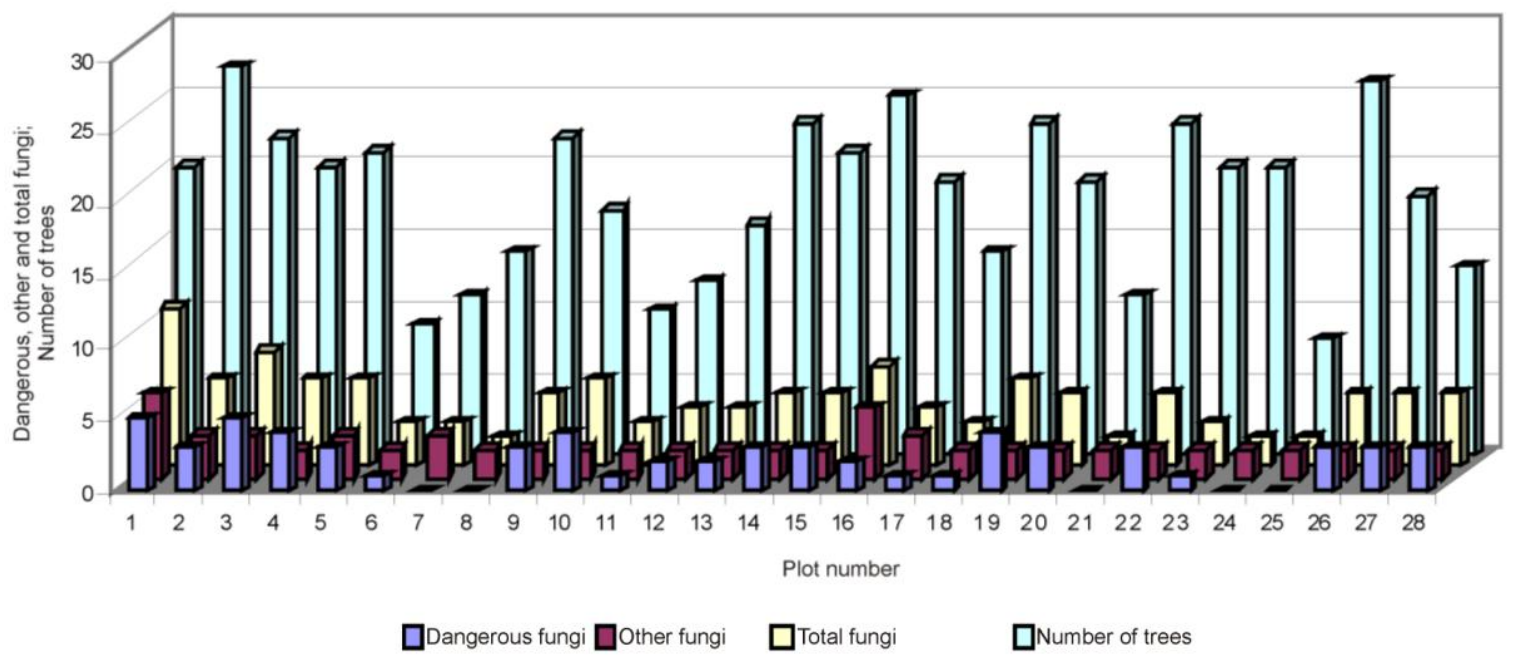

Figure 6. Site II - number of trees, number of dangerous and other fungi and total number of fungi per plot (from Table 4). 


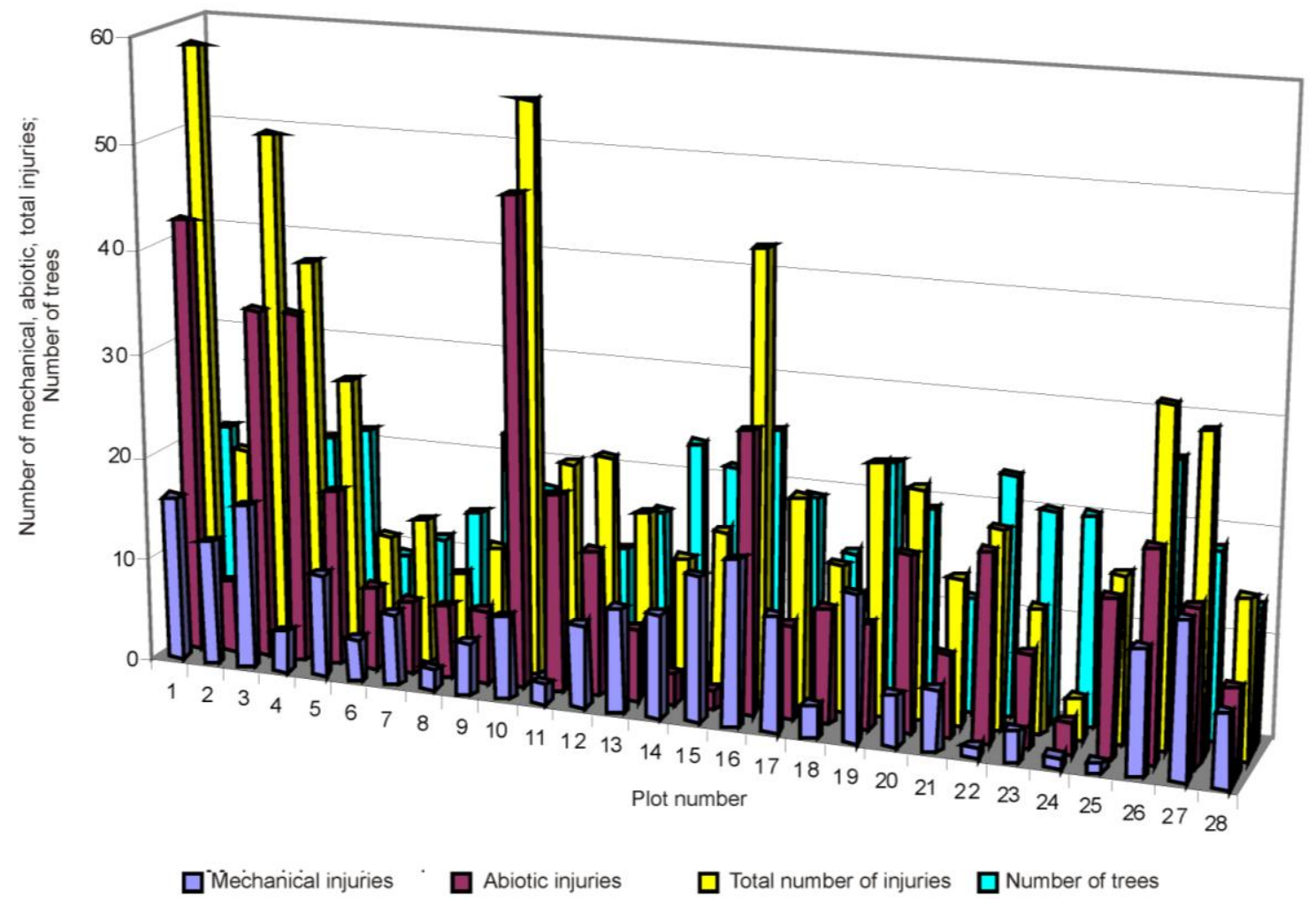

Figure 7. Site II - number of trees, number of mechanical injuries, number of abiotic injuries and total number of injuries per plot (from Table 4).

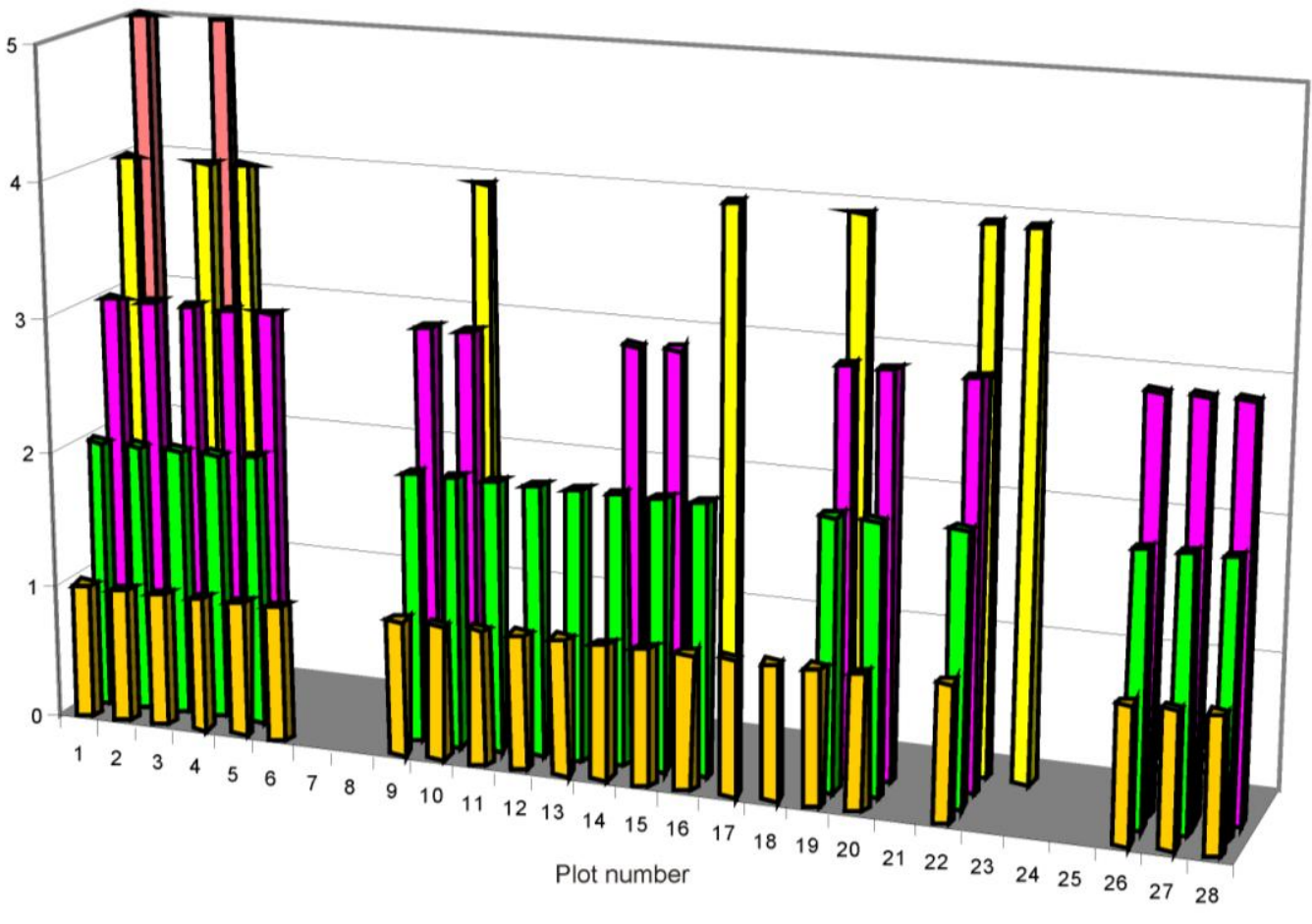

$\square^{\text {Rb. } 2} \square^{\text {Rb. } 4} \square^{\text {Rb. } 5} \square^{\text {Rb. } 7} \square^{\text {Rb. } 11}$

Figure 8. Site II - number of dangerous fungi per plot (from Table 2). 


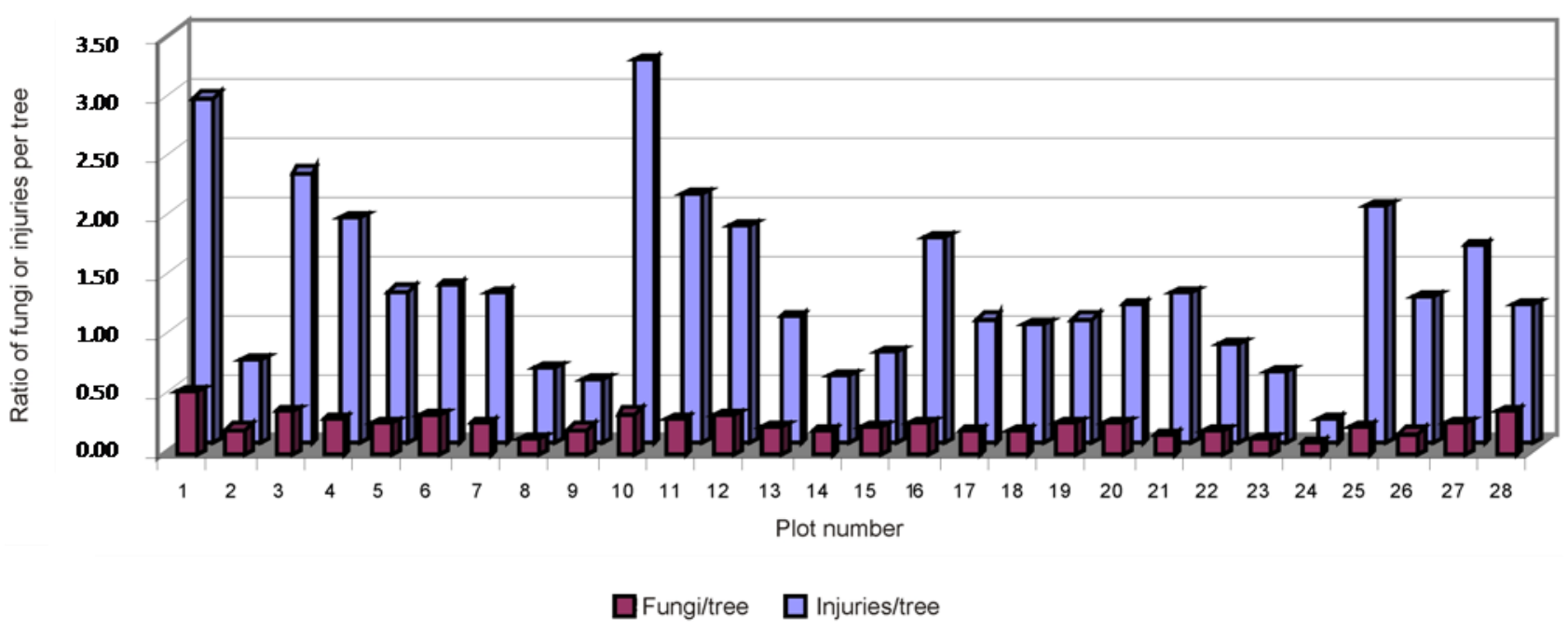

Figure 9. Site II - ratio between the total number of fungi per tree and the total number of injuries per tree (from Table 4).

value of correlation is expressed by correlation coefficient, most frequently Pearson's or Spearman's. A presentation of correlation results always includes the correlation coefficient " $r$ " written in a number with two decimal places, as well as significance of correlation coefficient " $P$ " in a number with three decimal places (according to Lang, 2004). Correlation coefficient shows to which degree changes of value of one variable are connected to changes of value of the other variable. The correlation coefficient number sign (+ or -) indicates the direction of such connection (Lang, 2004; Udovicic et al., 2007). This paper used Pearson linear correlation coefficient to calculate the relationship between two variables. The basic characteristics of Pearson linear correlation coefficient are as follows:

- dimensionless value, that is, no unit of measurement.

- values of linear correlation coefficient in the range from 1 to 1.

- in the calculation process, variables denoted as $x$ and $y$ may switch places without any impact on the final value of correlation coefficient.

- values ranging from 0 to 1 indicate positive relationship, that is, increase in one variable is followed by the increase of the other variable.

- values ranging from -1 to 0 indicate negative relationship, that is, increase in one variable is followed by decrease of the other variable.

$-r^{2}(R)$ is the coefficient of determination representing the proportion of common variability of the two variables.

Interpretation of Pearson linear correlation coefficient, that is, the strength of correlation (the interpretation remains the same for negative values of the correlation coefficient) is expressed as follows:

$-\geq 0.70$ strong correlation,
$-0.30-0.69$ medium correlation, $-<0.30$ weak correlation.

while at around 0.0 there is no linear correlation (which does not exclude non-linear forms of correlation).

Data presented in Table 3 (Site I) were used in statistical analysis to calculate Pearson linear correlation coefficient (Sosic, 2006) between the total number of fungi $\left(y_{3}\right)$ and the number of trees per plot $(x)$, as well as between the total number of mechanical and abiotic injuries $\left(x_{3}\right)$ and the number of trees per plot $\left(x^{\prime}\right)$. The linear correlation coefficient between the total number of fungi $\left(y_{3}\right)$ and the number of trees per plot $\left(x^{\prime}\right)$ was 0.59 , indicating a medium correlation between these two values. The linear correlation coefficient between the total number of mechanical and abiotic injuries $\left(x_{3}\right)$ and the number of trees per plot $\left(x^{\prime}\right)$ was 0.49 , an indication of medium correlation between the two values.

Data presented in Table 4 (Site II) were used to calculate Pearson linear correlation coefficient between the total number of fungi $\left(y_{3}\right)$ and the number of trees per plot $\left(x^{\prime}\right)$, as well as between the total number of mechanical and abiotic injuries $\left(x_{3}\right)$ and the number of trees per plot $(x)$. The linear correlation coefficient between the total number of fungi $\left(y_{3}\right)$ and the number of trees per plot $\left(x^{\prime}\right)$ was approximately 1 , indicating a strong correlation between these two values. The linear correlation coefficient between the total number of mechanical and abiotic injuries $\left(x_{3}\right)$ and the number of trees per plot $(x)$ was also about 1 , again indicating a strong correlation between the two values.

It is a well-known fact that health status of the stands is contingent upon a large number of factors, among which year-round climatic conditions must be considered as one of the most critical. Rainy, humid and relatively warm weather favours the activity of the fungi and increases the yield, and thus enables not only faster colonization by the 
fungi but also more precise identification of the existing microflora. It should also be noted that diagnosis of the disease is greatly impeded by long incubation of the fungi colonizing vital trees, while primary symptoms appear on the surface only after several years of attack (reproductive organs - visible carpophores may not appear at all or their appearance might be extended over a number of years). In addition to an accurate diagnosis, it is essential to make a precise prognosis of the dynamics of development of pathological processes in the plant. However, this prognosis cannot be determined with any reliable level of accuracy for the upcoming calendar years, as climatic conditions are a determining factor for the development of the infection. It is thus possible to make only a rough prognosis, based on mapping the parts of the forest under attack according to the destructor species and attack intensity, and use it as basis for planning the sanitary and silvicultural activities.

Sanitation felling and other phytosanitary measures, which may or may not be carried out in forests, certainly have a great impact on general health condition of the stands. Proper stewardship can minimize the existing infections and thus eliminate or greatly mitigate any new infection, which significantly contributes to having the health status of the stands restored and maintained on a satisfactory level.

\section{DISCUSSION}

Although beech is generally not regarded as high-quality wood (McLaughin and Greifenhagen, 2012), the dominance of beech forests in Serbia makes preservation of healthy beech stand reserves of utmost importance for the region's forest economy. This is an issue that must be addressed from multiple aspects due to high sensitivity of beech wood to development of diseases and pests, as well as due to climatic changes occurring on a global level. According to Vasiliauskas (2001), the majority of hardwood trees such as beech, hornbeam and alder are susceptible to injury infection, and variations in injury infection frequency could be attributed to factors such as difference in size, position of injury on a tree and season of injury. Study of Yilmaz and Akay (2008) in a forest of Turkey showed similar results. The most important pathological consequence of mechanical damage to standing trees is development of decay in injuries.

Changing climate causes long-term significant changes to structural and spatial characteristics of the global biodiversity. Based on the changes of climatic parameters found to date, as well as on consideration of various climate change scenarios (global, regional), the territory of Serbia falls into the category of areas in which climatic changes have jeopardized not only sustainable use of natural resources, but consequently the state of the environment as well. As a result of increase of air temperatures, lower rainfall during summer months and larger number of prolonged dry spells, drought periods in Serbia have already been found to be increasing in frequency, intensity and duration.

In the part of their work related to links between occurrence of dangerous beech bark disease and climatic changes, taking into account the available references on the subject, (Kasson and Livingston, 2011) claim that a major drought period from 1999 to 2002 coincided with growth decline and a significant increase in beech mortality across all regions included in this study. Neonectria was found infecting weakened trees across the region, while drought, beech scale and Neonectria were plausible explanations for the episode of high beech mortality in northern Maine.

In Serbia, whose territory lies within the area with the highest frequency of drought, this trend is particularly strong in eastern and south-eastern regions. Since prolongation of the vegetation period is expected in the upcoming period, this particular part of Serbia was selected for research.

During the research it was found that this area (although with a high number of days without precipitation) still has relatively stable changes of climatic elements year-round. Both tested sites are located in fairly close proximity and have similar climatic conditions; hence this factor had no effect on the obtained results.

It is therefore safe to say that occurrence and development of diseases in this region is largely caused by other factors. According to Sinclair and Lyon (1995), diseases caused by biological agents are separated from those caused by environmental stimuli.

Among the major factors that came into focus of the research was presence of open injuries on trees, given that they represent an open road for colonization of fungi. The results show that health condition of beech stands in this region is fairly poor, whereby an alarming number of injuries on trees was detected, caused by the effects of multiple agents. Considering that in practice we can only reduce the number of injuries caused by the anthropogenic factor (that is, those inflicted during felling and handling), it is crucial to ensure that these tasks are conducted with utmost care. As stated by Tavankar et al. (2013), to reduce the stand damage, skid trails should be planned before felling and felling directions should be predetermined.

Through research conducted in this paper, a large number of fungi dangerous to a lesser or higher degree were detected to be present on the tested beech stands. Among the more frequent highly dangerous fungi found in this area is the beech bark disease (BBD), caused by joint effect of fungi of Nectria species and the insect Cryptococcus fagisuga. The sources from literature on the subject state that beech bark disease is a major problem in other parts of the world, while control measures are very difficult to enforce (Fernandez and Boyer, 1988; Leak, 2006; Noble, 2009; Ostrofsky, 2005; Le Guerrier et al., 2003; Houston, 1994). The Nectria fungus cannot be controlled, once it infects the tree. 
Heavy infection may lead to stem breakage. Where beech is a major component of the stand and trees are heavily affected by BBD, management can be challenging. Removal of infected trees can result in prolific root sprouting, causing susceptible, low-value trees to regrow (Mc Laughin and Greifenhagen, 2012).

\section{Conclusions}

Two experimental sites (Site I and Site II) with over 50 test plots on which the research was conducted were exposed to roughly similar environmental conditions (climate, altitude, geological base, etc.). However, there are substantial differences between the results of testing the mutual relationship between injuries on trees and occurrence of fungi.

On the first test site (Site I), the results given here below were obtained based on calculation of Pearson linear correlation coefficient between the total number of fungi $\left(y_{3}\right)$ and the number of trees per plot $\left(x^{\prime}\right)$, as well as the total number of mechanical and abiotic injuries $\left(x_{3}\right)$ and number of trees per plot $(x)$ : The linear correlation coefficient between the total number of fungi $\left(y_{3}\right)$ and the number of trees per plot $(x)$ was 0.59 , indicating a medium correlation between these two values. The linear correlation coefficient between the total number of mechanical and abiotic injuries $\left(\mathrm{x}_{3}\right)$ and the number of trees per plot $(x)$ was 0.49 , also an indication of medium correlation between the two values. This effectively means that on site one the occurrence of fungi was only partially linked to the presence of mechanical and abiotic injuries and that was it largely contingent upon other factors.

On the second test site (Site II), the results presented here below were obtained by calculating Pearson linear correlation coefficient between the total number of fungi $\left(y_{3}\right)$ and the number of trees per plot $\left(x^{\prime}\right)$, as well as between the total number of mechanical and abiotic injuries $\left(x_{3}\right)$ and the number of trees per plot $\left(x^{\prime}\right)$ : The linear correlation coefficient between the total number of fungi $\left(y_{3}\right)$ and the number of trees per plot $\left(x^{\prime}\right)$ was approximately 1 , indicating a strong correlation between these two values. The linear correlation coefficient between the total number of mechanical and abiotic injuries $\left(x_{3}\right)$ and the number of trees per plot $\left(x^{\prime}\right)$ was also about 1 , again indicating a strong correlation between the two values. Therefore, a significant correlation was found on site two between abiotic and mechanical injuries and the number of present fungi, which was in this case a consequence of an extremely high number of injuries.

Upon examining the results obtained through comparative analysis of sites one and two, it can be concluded that the number of injuries is the determining factor in linking the occurrence of fungi and damage on trees. On sites with a smaller number of injuries the correlation between the presence of fungi and injuries on trees is weaker, and vice versa.
Finally, the fact that a large number of external factors are beyond our scope of influence leads to an overall conclusion that careful and proper handling during felling is crucial for health condition of high beech stands, therefore the number of injuries inflicted during field work needs to be reduced to a minimum. Each injury to standing beech trees inflicted during felling opens the door to infection by pathogenic microorganisms, and the higher the number of injuries, the higher the likelihood of occurrence and spreading of dangerous infections.

In any event, proper stewardship can reduce the existing infections to the lowest extent, which would in turn eliminate or significantly alleviate new infections. This would greatly contribute to improving the present poor health condition of beech stands in Serbia and sustaining it on a satisfactory level in the future.

\section{ACKNOWLEDGEMENTS}

The study was carried out within the Project TP-31070: "The development of technological methods in forestry in order to attain optimal forest cover", financed by the Ministry of Education and Science of the Republic of Serbia within the framework of integrated and interdisciplinary research for the period $2011-2014$.

\section{REFERENCES}

Bankovic S, Medarevic M, Pantic D, Petrovic N (2009). National Forest Inventory of the Republic of Serbia - Growing stock of Republic of Serbia. Ministry of Agriculture Forestry and Water Management Serbia - Management of Forests, Belgrade, Serbia, pp. 1-244.

Fernandez MR, Boyer MG (1988). Beech bark disease - A survey of the Toronto area. Can. Plant Dis. Surv. 68(2):157-159.

Houston DR (1994). Major new tree disease epidemics: Beech bark disease. Ann. Rev. Phytopathol. 32:75-87.

Ivkovic S, Markovic M, Miric M (2007). Growth and mycelial mass production of wood - decaying fungus Trametes versicolor (Fr.) Pil. and Coniophora puteana (Schum.:Fr.) Karst in controled temperature and $\mathrm{pH}$ conditions. International Scientific Conference "Integral protection of Forests Scientific - Technological platform." Belgrade, 12.12.2007, Book of Abstracts, pp. 95-96.

Karadzic D (2003). The most important disease of the beech forests in Serbia. Forestry 1-2:59-72.

Karadzic D, Milijasevic T (2005). Beech (Fagus moesiaca / Domin, Mally / Czeczott.) in Serbia. Monography, Chapter 3, Faculty of Forestry, Belgrade, Serbia, pp. 179-196.

Kasson MT, Livingston WH (2011). Relationships among beech bark disease, climate, radial growth response and mortality of American beech in northern Maine, USA. For. Path. DOI: 10.1111/j.14390329.2011.00742.x

Kiser JD (2009). The effects of mechanical damage on residual coastal Douglas-fir (Pseudotsuga menziesii [Mirbel] Franco following commercial thinning, Dissertation, ProQuest, Wood Sciences, p. 168.

Koprivica M, Matovic B, Markovic N (2008). Qualitative and assortment structure of high beech stand volume in Severnokucajsko forest area. Forestry 60(1-2):41-52 [in Serbian].

Lang T (2004). Twenty Statistical Errors Even YOU Can Find in Biomedical Research Articles. CMJ 45(4):361-370.

Le Guerrier C, Marceau DJ, Bouchard A, Brisson J (2003). A modelling approach to assess the long-term impact of beech bark disease in northern hardwood forest. Can. J. For. Res. 33:2416-2425.

Leak WB (2006). Fifty-year impacts of the beech bark disease in the 
Bartlett experimental forest, New Hampshire. North. J. Appl. For. 23: 141-143.

Markovic M, Rajkovic S, Miric M, Mitic D, Milovanovic J, TabakovicTosic M (2011a). Colonization of the substrate of wood - decaying fungi Fomitopsis pinicola (Sw.:Fr.) P. Karst. isolated from beech and fir under controlled temperature and $\mathrm{pH}$ conditions. Fresenius Environ. Bull. 20(3):583-589.

McLaughlin J, Greifenhagen S (2012). S. Beech Bark Disease in Ontario: A Primer and Management Recommendations, Forest Reseach Note, Ontario Forest Research Institute, ISSN 0381-2650, 71:1-8.

Miletic Z, Markovic M, Tabakovic-Tosic M (2006). Effect of Diferent Soil Types on Hazard to Beech Caused by the Fungi in the Genus Nectria in M.U. Majdan-Kucajna. International. Scientific Conference in occasion of 60 year of operation of Institute of Forestry, Belgrade, Serbia. Sustainable Use of Forest Ecosystems-The Challenge of the $21^{\text {st }}$ Century, 8-10 November, Donji Milanovac, Proceedings, pp. 297302.

Milovanovic D, Krstic M, Babic V (2004). Significance of productive and social functions for the beech forests in Serbia. Forestry 1-2:105-116.

Noble TJ (2009). Beech bark disease and its impacts on mast production and mortality in American beech, Fagus grandifolia. Trent University, Environment and Life Science Programme, Peterborough, ON. M.Sc. Thesis, $131 \mathrm{p}$.

Ostrofsky WD (2005). Management of beech bark disease in aftermath forests. In: C.A. Evans, J.A. Lucas, M.J. Twery (eds). Beech Bark Disease: Proceedings of the Beech Bark Disease Symposium, Sarnac Lake, NY, June 16-18, 2004. USDA Forest Services, Northeast Research Station, Gen. Tech. Rep. NE-331, 149 p.

Say WC (1999). Natural Mechanical Damage in Silver Beech Forest, Dissertation, University of Canterbury, New Zealand, p. 148.

Sinclair WA, Lyon HH (2005). Diseases of Trees and Shrubs, 2 ed. Cornell University Press, Ithaca, NY. 660 p.

Sosic I (2006). Applied Statistics, pp. 379-546.

Tabakovic-Tosic M, Markovic M (2003). Harmful biotic factors in beech copice forests of east Serbia. International Scientific Conference, 75 years of the Forest Research Institute of Bulgarian Academy of Sciences, 1-5 October. Sofia. Bulgaria Proc. Sci. Pap. 2:239-246.
Tavankar F, Majnounian B, Bonyad AE (2013). Felling and skidding damage to residual trees following selection cutting in Caspian forests of Iran. J. For. Sci. 59 (5):196-203.

Udovicic M, Bazdaric K, Bilic-Zulle L, Petrovecki M (2007). What to know when calculating the correlation coefficient? Biochemia Medica 17(1):10-15.

Vasiliauskas $R$ (2001). Damage to trees due to forestry operations and its pathological significance in temperate forest: A literature review. Forestry 74(4):319-336.

Yilmaz M, Akay A (2008). Stand damage of a selection cutting system in an uneven aged mixed forest of Cimendagi Kahramanmaras Turkey. Int. J. Nat. Eng. Sci. 2(1):7-82. 